\title{
IV SIMPOSIO NACIONAL DE FILOSOFÍA ANTIGUA: "Educación, arte y política en la Filosofía Antigua"
}

\author{
Castillo Merlo, Mariana \\ IV SIMPOSIO NACIONAL DE FILOSOFÍA ANTIGUA: "Educación, arte y política en la Filosofía Antigua" \\ Synthesis, vol. 26, núm. 2, 2019 \\ Universidad Nacional de La Plata, Argentina \\ Disponible en: http://www.redalyc.org/articulo.oa?id=84662943010 \\ DOI: https://doi.org/10.24215/1851779Xe067
}

Esta obra está bajo una Licencia Creative Commons Atribución-NoComercial-Compartirlgual 4.0 Internacional. 


\section{SIMPOSIO NACIONAL DE FILOSOFÍA ANTIGUA: "Educación, arte y política en la Filosofía Antigua"}

Mariana Castillo Merlo

IPEHCS-UNCO-CONICET, Argentina
DOI: https://doi.org/10.24215/1851779Xe067

Redalyc: http://www.redalyc.org/articulo.oa?id=84662943010

En el Centro de Posgrado de la Universidad Nacional de La Plata, durante los días 28, 29 y 30 de agosto de 2019, tuvo lugar el IV Simposio Nacional de Filosofía Antigua. En esta ocasión, el tema elegido por la Asociación Argentina de Filosofía Antigua (AAFA) para congregar a los estudiosos del mundo clásico fue "Educación, arte y política en la Filosofía Antigua".

El acto inaugural estuvo a cargo de la Presidenta del Comité Organizador, Dra. Viviana Suñol, el Presidente de la Asociación, Dr. Manuel Berrón, y la Directora del Centro de Estudios Helénicos, Dra. Claudia Fernández. Además de ser los encargados de darles una cordial bienvenida a los participantes y asistentes, Suñol, Berrón y Fernández fueron quienes cuidaron cada detalle de la organización y se constituyeron, sin lugar a dudas, en los pilares del Simposio. En un contexto nacional poco favorable, la organización de reuniones científicas de este tipo da cuenta de una fuerte apuesta al convivium, a la necesidad de fortalecer los lazos de la comunidad filosófica, a la generación de espacios de diálogo y escucha y por todo ello, reflejan el compromiso político y la tenacidad de quienes, a pesar de las adversidades, deciden llevar adelante eventos de excelencia académica como este.

Durante los tres días del Simposio, se dieron cita especialistas en estudios clásicos de la gran mayoría de las universidades del país, además de las de Uruguay, Brasil, Chile, Colombia y México. Las actividades de los noventa participantes estuvieron organizadas en torno a nueve mesas temáticas y dieciséis sesiones de ponencias individuales, a las que se sumaron la presentación del libro compilado por los Dres. Julian Gallego (UBA) y Claudia Fernández (CEH-UNLP) Democracia, pasión de multitudes. Politica, comedia y emociones en la Atenas clásica y del dossier "Amor, inspiración y logos en el pensamiento antiguo" de la Revista Nuevo Itinerario, editado por las Dras. María Angélica Fierro (UBA) y Ana Carolina Delgado (UNGS).

Las conferencias centrales estuvieron a cargo del Dr. Eduardo Sinnot (USAL, Argentina) y la Dra. Virginia Aspe Armella (UP, México). Sinnot disertó “Acerca de la iconicidad en Aristóteles" con un trabajo que dio muestras, por un lado, de su vasta trayectoria y erudición en la temática y, por otro, subrayó nuevas hipótesis sobre el valor descriptivo y hermenéutico de la noción de signo icónico en la estética aristotélica. Por su parte, Aspe Armella con la calidez que la caracteriza, nos ilustró con un exquisito trabajo de historia intelectual acerca de la importancia de la filosofía antigua en el período colonial de México, la pertinencia del aristotelismo de cara a los problemas actuales de América y las razones de “¿Por qué es importante recuperar en América la tradición fundacional aristotélica?”.

En el marco del Simposio también tuvo lugar la Asamblea Ordinaria de la Asociación como espacio de encuentro e intercambio entre los especialistas del área, quienes realizaron un balance del trabajo realizado en los últimos años y de la situación financiera de la Asociación. Además, se presentaron propuestas para fomentar interés y la participación en las actividades del área. Un tema recurrente de discusión, no solo para quienes asistimos sino, y principalmente, para quienes llevaron adelante la organización del Simposio, fue el financiero. En días de incertidumbre económica y corridas del dólar, era inevitable hablar de ello en cada pausa, café y medialunas mediante.

Las dificultades políticas y económicas por las que atraviesa nuestro país no pueden ser ajenas a la comunidad científica. La importancia del Simposio y del esfuerzo realizado por sus organizadores y 
colaboradores, en este contexto tan particular en el que los subsidios se otorgan pero no se efectivizan, en el que el poco dinero con el que se cuenta pierde su valor a cada paso, cobra otra magnitud. Celebro el encuentro entre colegas y el tiempo de reflexión, discusión y análisis de las conexiones entre "educación, arte y política en la Filosofía Antigua”. Celebro que pensar el mundo clásico, en estos días de tanta convulsión en los que nuestras democracias latinoamericanas son vapuleadas, sea también una excusa para pensar el rol de la educación y el arte en la vida política. Celebro que el Simposio haya sido el pretexto necesario para encontrarnos y pensarnos a nosotros mismos.

Mariana Castillo Merlo

IPEHCS-UNCO-CONICET

CC BY-NC-SA 